\title{
Medial arterial calcification in diabetes and its relationship to neuropathy
}

\author{
W. J. Jeffcoate • L. M. Rasmussen • L. C. Hofbauer • \\ F. L. Game
}

Received: 18 March 2009/Accepted: 2 June 2009/Published online: 12 September 2009

(C) Springer-Verlag 2009

\begin{abstract}
Calcification of the media of arterial walls is common in diabetes and is particularly associated with distal symmetrical neuropathy. Arterial calcification also complicates chronic kidney disease and is an independent risk factor for cardiovascular and all-cause mortality. The term calcification is not strictly accurate because the morphological changes incorporate those of new bone formation, i.e. ossification. The processes are complex, but are closely related to those involved in bone homeostasis, and it is relevant that calcification of the arterial wall and osteopenia often co-exist. One particular factor linked to the development of arterial calcification is distal symmetrical neuropathy; indeed, it has been suggested that neuropathy explains the distal distribution of arterial calcification in diabetes. It has also been suggested that the link with neuropathy results from loss of neuropeptides, such as calcitonin gene-related peptide, which are inherently protective. The association between distal symmetrical neuropathy and calcification of the arterial wall highlights the fact that neuropathy may be an independent risk factor for cardiovascular mortality.
\end{abstract}

\footnotetext{
W. J. Jeffcoate $(\bowtie) \cdot$ F. L. Game Department of Diabetes and Endocrinology, Nottingham University Hospitals Trust,

City Hospital Campus,

Nottingham NG5 1PB, UK

e-mail: william.jeffcoate@nuh.nhs.uk

L. M. Rasmussen

Department of Biochemistry, Pharmacology and Genetics, Odense University Hospital,

Odense, Denmark

L. C. Hofbauer

Division of Endocrinology, Diabetes, and Bone Diseases, Department of Medicine III, Technical University, Dresden, Germany

Keywords Cardiovascular disease · Diabetes · Medial artery calcification · Neuropathy - Osteoporosis · Osteoprotegerin . RANKL $\cdot$ Renal disease $\cdot$ Review

$\begin{array}{ll}\text { Abbreviations } \\ \text { BMP } & \text { Bone morphogenetic protein } \\ \text { Cbfa1 } & \text { Transcription factor core-binding protein } \\ \text { CGRP } & \text { Calcitonin gene-related peptide } \\ \text { CVC } & \text { Calcifying vascular cells } \\ \text { DSN } & \text { Distal symmetrical neuropathy } \\ \text { MAC } & \text { Medial artery calcification } \\ \text { MGP } & \text { Matrix Gla protein } \\ \text { MSX-2 } & \text { Msh homeobox } 2 \\ \text { NF-kB } & \text { Nuclear factor kappa-B } \\ \text { PPAR } & \text { Peroxisome proliferator-activated receptor } \\ \text { RANK } & \text { Receptor activator for nuclear factor } \mathrm{kB} \\ \text { RANKL } & \text { Receptor activator for nuclear factor } \mathrm{kB} \text { ligand } \\ \text { TRAIL } & \text { TNF-related apoptosis-inducing ligand } \\ \text { VEGF } & \text { Vascular endothelial growth factor } \\ \text { VSMC } & \text { Vascular smooth muscle cells }\end{array}$

\section{Introduction}

Calcification of the media or medial artery calcification (MAC) was first described by the German pathologist, J. G. Mönckeberg, in 1903 [1] and is also known as Mönckeberg's sclerosis. Mönckeberg's article pointed out that the changes were most prevalent in the distal arteries of the limbs [1]. MAC is frequently observed in patients with diabetes and is associated with increased risk of nephropathy, retinopathy, major amputation, coronary artery disease and all-cause mortality $[2,3]$. Many processes are involved in the pathogenesis of MAC, which in diabetes is thought to 
be particularly associated with distal symmetrical neuropathy (DSN). The aim of this review is threefold: (1) to provide an overview of the active and passive processes involved in arterial wall calcification; (2) to highlight the potential mechanisms linking DSN to MAC in diabetic patients; and (3) to consider the implications of MAC in clinical practice.

\section{Calcification of the arterial intima and media}

Calcification of the intima is a feature of atheroma (atherosclerotic calcification), is eccentric, associated with luminal narrowing and tends to be more proximal. In contrast, MAC tends to be concentric and symmetrical, and is a common feature of more distal arteries in diabetes. Essentially, however, the change which takes place in both cases is not limited to calcification by passive mineral deposition, but involves active ossification and de novo bone formation, as was first noted by Rudolf Virchow in 1863 (Fig. 1) [4]. No studies have been undertaken to determine the relative frequencies with which passive calcification and ossification may be observed. Intimal calcification, however, tends to have the histological features of endochondral bone formation, whereas MAC is more typically membranous [5], although endochondral bone formation can also be observed in MAC [6].

Numerous factors cause, trigger or exaggerate the process of arterial calcification, and have been extensively studied and reviewed in recent years [5,7-10], mirroring to a large extent factors that promote atherogenesis. They include: physical intra-arterial forces; antigens stimulating immune responses from the dendritic cells, T cells and macrophages adjacent to the endothelium; oxidative stress; high ambient glucose concentrations with increased AGE, insulin, reactive oxygen species and oxidised LDL; pro-inflammatory cytokines; and factors triggering the release of TGF- $\beta$.

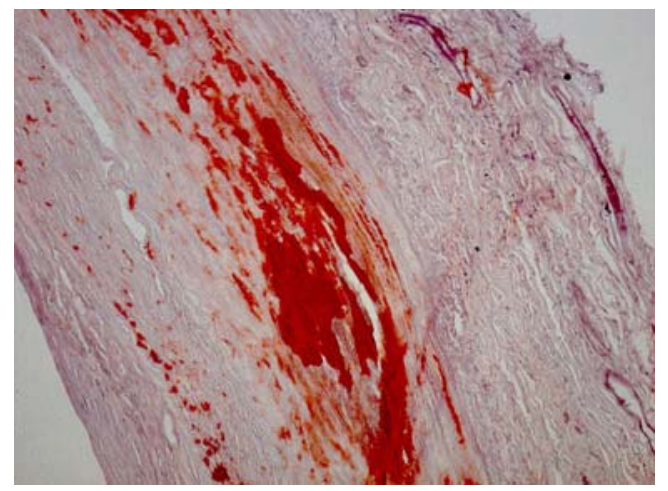

Fig. 1 Cross-section through a human tibial artery with both small foci of calcification and larger calcific deposits within the tunica media, stained with Alizarin Red. Illustration kindly provided by M. Y. Alexander (Cardiovascular Research Group, University of Manchester, UK)
Phosphate accumulation is important in chronic kidney disease, as are vitamin D deficiency and hyperparathyroidism. Arterial calcification is also potentiated by increases in calcium and phosphate ions resulting from enhanced bone turnover and is commonly associated with osteoporosis. Moreover, calcification is influenced by several other local growth factors (including IGF-1) and systemic hormones (including oestrogens and thyroid hormones).

Although the factors leading to MAC in chronic kidney disease have been well reviewed [11], those involved in causing MAC in diabetes are more complex and less well understood. The association between MAC and DSN in diabetes is recognised, but the mechanisms underlying the association, and its clinical significance, have not been previously considered in detail.

\section{Cellular aspects of arterial calcification}

The cellular processes involved comprise differentiation of cells with bone-forming (osteogenic) potential, matrix vesicle formation and both apoptotic and non-apoptotic calcification (Fig. 2).

Origin of bone forming (osteogenic) cells Osteogenic cells are thought to be derived from pluripotential, mesenchymal stem cells, which originate principally from the bone marrow and are seeded from the circulation into the target tissues, where they retain the capacity to differentiate and, crucially in the process of arterial calcification, dedifferentiate and re-differentiate (or 'trans-differentiate') into cells with different phenotypic features and functions [12].

Mesenchymal stem cells respond to potentially harmful stimuli by secreting bone morphogenetic proteins (BMPs), which trigger the differentiation of osteogenic cells. BMP-2 was first shown to be associated with calcification in human atherosclerotic plaques by Boström and colleagues [13]. A complex nomenclature hampers understanding of these processes, with cells of bone-forming potential variously referred to by different researchers, depending on their position in the arterial wall and their state of differentiation, as pericytes, vascular smooth muscle cells (VSMCs), calcifying vascular cells (CVCs) and adventitial cells. VSMCs and CVCs are themselves derived from pericytes and adventitial cells. Pericytes may differentiate along one of several pathways into VSMCs and CVCs, endothelial cells [14] and adipocytes [15].

Determinants of cellular differentiation BMPs induce osteogenic change via a variety of transcription proteins including Runx-related, transcription factor core-binding protein (Cbfa1), msh homeobox 2 (MSX-2), osterix, and 
Fig. 2 Schematic diagram indicating some of the multiple processes likely to be media of arterial walls in diabetes. Red, inhibitors of mesenchymal stem cells; NO, nitric oxide; $\mathrm{OPG}$, osteoprotegerin; PTH, parathyroid hormone; ROS, reactive oxygen species involved in ossification of the calcification/ossification. MSCs,

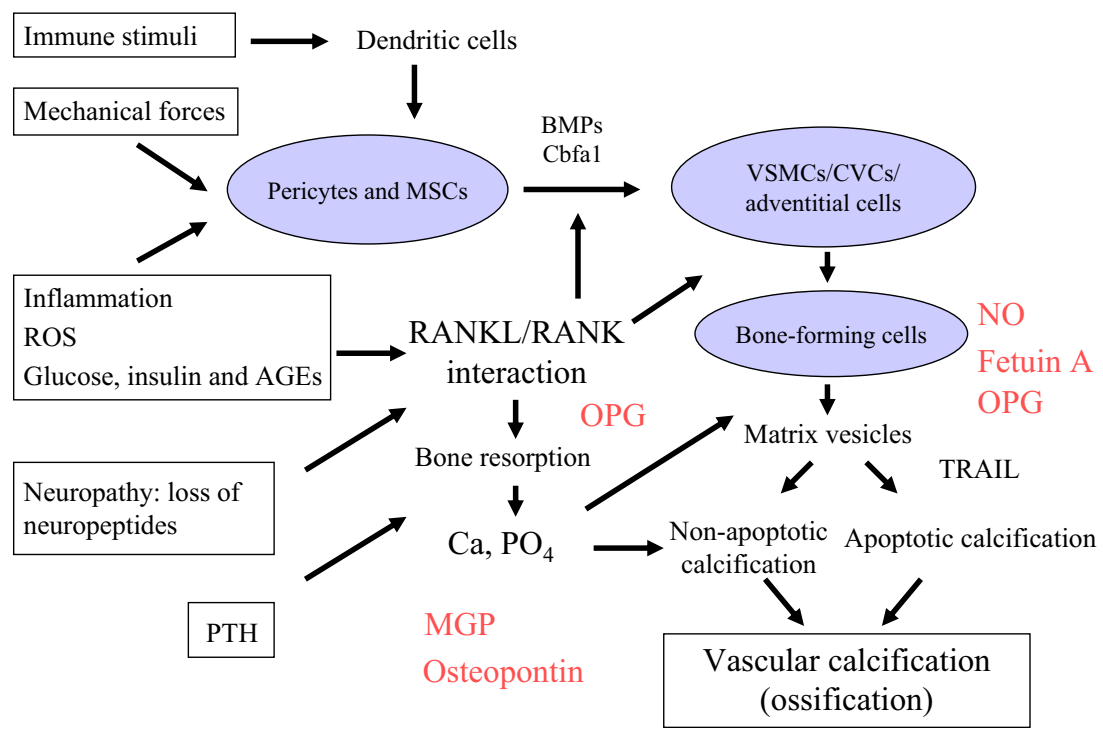

SRY (sex determining region Y)-box 9 (SOX9) [16]. MSX2 is required for membranous bone formation, whereas Cbfa1 is necessary for osteoblastic transformation, neovascularisation and endochondral ossification [17]. SOX9 may determine whether ensuing ossification is endochondral or membranous in type [6]. The actions of BMPs on target cells such as VSMCs are to some extent conflicting, suggesting the existence of intrinsic autoregulatory and overlapping mechanisms.

In response to BMP-2 and BMP-4, VSMCs 'transdifferentiate' into non-contractile cells with bone-forming capacity and acquire properties of osteoblasts, i.e. ability to synthesise alkaline phosphatase, bone sialoprotein, osteocalcin and type I collagen [18]. It is likely that 'transdifferentiated' VSMCs share with normal osteoblasts the capacity to elaborate another TGF- $\beta$-related protein, namely the pleiotropic hormone, activin-A, as well as its glycoprotein antagonists, follistatin and follistatin-related proteins $[19,20]$. Activin-A production is another example of the potential for complex autoregulation, as it inhibits mineralisation. Activin-A is also involved in promoting neovascularisation, where its actions are potentiated by basic fibroblast growth factor-2. Activin-A and vascular endothelial growth factor (VEGF) each upregulate production of the other in bovine VSMCs in culture [21].

Intriguingly, BMP-2 and BMP-4 are also involved in the early development of autonomic and somatic sensory nerves, and in regulating levels of different neuropeptides by modulation of specific peptidergic systems [22]. This may be relevant to the putative role of autonomic and somatic sensory nerves in regulation of calcification of the arterial wall (see below).

Matrix vesicle formation Matrix vesicle formation is a feature of normal osteogenesis [23]. The vesicles are just over $100 \mathrm{~nm}$ in diameter and are enclosed in a tri-lamellar catalyses the breakdown of pyrophosphate, itself an inhibitor of calcification. Phosphate is actively transported into the vesicle by a sodium-dependent phosphate pump. The pumping of phosphate ions into the vesicle is itself potentiated by increased phosphate concentration in the extracellular fluid, as occurs in states of enhanced bone resorption and in chronic renal failure. Matrix vesicles also contain calcium-binding proteins. The vesicle membrane later disintegrates and this allows the calcium phosphate to come into contact with extracellular matrix constituents, triggering the formation of mature crystals of hydroxyapatite [24].

Apoptosis The extrusion of matrix vesicles by VSMCs and related osteogenic cells may be partly stimulated when these cells undergo apoptosis, leading to apoptotic bodies, which behave in a similar fashion [24]. Apoptosis may itself result from a variety of factors, including the action of TNF- $\alpha$ and two members of the TNF superfamily, namely: (1) receptor activator of nuclear factor kappa $\mathrm{B}(\mathrm{NF}-\mathrm{kB})$ (RANK) ligand (RANKL); and (2) TNF-related apoptosisinducing ligand (TRAIL). The actions of both of these are inhibited by the glycoprotein, osteoprotegerin. Both the apoptotic cells and the surrounding matrix may become calcified.

Degradation of elastin Degradation of elastin occurs during the development of arteriosclerosis. It may be the consequence of proliferation of VSMCs [24]. Without membrane. They are rich in alkaline phosphatase, which

\section{Other cellular processes involved in calcification of the arterial wall}


elastin, however, collagen becomes the principal extracellular component of the arterial wall, which becomes stiffer as a result, especially when collagen becomes glycated as in diabetes mellitus $[25,26]$. Elastin degradation products may facilitate the process of calcification. Thus rat fibroblasts exposed to elastin degradation products and TGF- $\beta$ become osteogenic and produce Cbfa1, osteocalcin, alkaline phosphatase and osteoprotegerin [27].

Neovascularisation New blood vessel formation is a key part of endochondral ossification, as well as the calcification that occurs in heart valves [28]. These new vessels derive from pericytes, as well as from other cells of mesenchymal lineage that are able to de-differentiate, including VSMCs. The key factor promoting neovascularisation is thought to be VEGF, although it is also promoted by bone sialoprotein and activin-A [21]. Recent evidence shows that production of VEGF, at least in developing bone, is itself triggered by production of hypoxia-inducible factor- $1 \alpha$ by osteoblasts [29].

Phosphate uptake VSMCs may also undergo calcification through a process that is independent of apoptosis. Li and colleagues have demonstrated that this can be mediated through intracellular accumulation of phosphate through the action of the sodium-dependent phosphate co-transporter, solute carrier family 20 (phosphate transporter), member 1 (PIT-1) [30]. Intracellular phosphate stimulates the activity of Cbfa1, which is an essential transcriptional factor for osteoblast differentiation.

\section{Factors known to influence the development of osteogenic cells and vascular calcification}

Fetuin- $A$ Fetuin-A is an acute-phase glycoprotein that is synthesised in the liver and acts as a carrier for growth factors [31]. It also inhibits the actions of BMP-2. A powerful inhibitor of hydroxyapatite formation, fetuin-A limits matrix vesicle formation. In addition, it reduces apoptosis and enhances phagocytosis (and hence inactivation) of matrix vesicles by VSMCs. Reduced synthesis of fetuin-A is a major factor leading to increased arterial calcification in chronic kidney disease [11]. Polymorphisms in the gene encoding fetuin-A are associated with poor cardiovascular outcome; indeed, an inverse correlation has been demonstrated between circulating concentrations of fetuin-A and cardiovascular and all-cause mortality in man [32].

Matrix Gla protein Matrix Gla protein (MGP) is present in VSMCs and, like osteocalcin, is one of a family of mineralbinding proteins that contain $\gamma$-carboxyglutamic acid, which has a high affinity for hydroxyapatite. MGP inhibits induction of alkaline phosphatase by BMPs [33]. MGPdeficient mice demonstrate extensive endochondral bone formation in the arterial wall, as well as generalised calcification of cartilage. In rats, inhibition of gammacarboxylation of MGP by warfarin is an established animal model of vascular calcification. There is evidence of complex coordination of the actions of fetuin A, MGP and other factors in the release of calcium and phosphate accompanying bone lysis [34].

Osteopontin Osteopontin (also known as bone sialoprotein-1) is a phosphoprotein secreted by a range of cell types (including pre-osteoblasts, osteoblasts and osteoclasts) and which has a correspondingly wide range of biological functions. It is a major constituent of bone matrix and has been shown to inhibit calcification by adhering to calcium apatite crystals [35]. However, it also stimulates osteoclast migration by binding to $\alpha_{v} \beta_{3}$-integrin expressed on the osteoclast cell surface. Patients with type 2 diabetes and calcification of peripheral arteries display higher circulating concentrations of osteopontin; the protein has also been found in increased amounts in the arterial wall of human diabetic patients and experimental animal models of diabetes [36].

Osteoprotegerin and its ligands, RANKL and TRAIL RANKL is a polypeptide hormone that leads to increased production of the nuclear transcription factor, NF- $\mathrm{KB}$, which in turn leads to maturation of pre-osteoclasts. Activation of this pathway is thought to be central to bone break-down, both in normal bone remodelling and in a wide variety of pathological states [37, 38]. This process, however, is modulated by a parallel action on osteoblasts, resulting in production of osteoprotegerin, which has structural similarity to the RANK receptor to which RANKL binds. Osteoprotegerin thus acts as a decoy receptor and effectively limits the action of RANKL. RANKL is a member of the TNF superfamily. Its production is regulated by TNF- $\alpha$ and other pro-inflammatory cytokines, including IL-1 $\beta$ and IL-6. TRAIL is another member of the TNF superfamily and induces apoptosis of osteogenic cells in the arterial wall (see above). The action of TRAIL, like that of RANKL, is inhibited by osteoprotegerin.

The observation by Bucay and colleagues [39] that osteoprotegerin-deficient mice not only had osteoporosis, but also extensive MAC of the aorta and renal arteries, led to the concept that the RANKL/osteoprotegerin signalling pathway may be intimately involved in calcification of the arterial wall, as well as in the regulation of bone turnover. Osteoprotegerin and osteoprotegerin mRNA, as well as TRAIL, have been observed to co-localise with areas of 
calcification in arterial wall, although levels of RANKL were much lower [40]. RANKL production is closely linked to that of TNF- $\alpha$ and other pro-inflammatory cytokines, and TNF- $\alpha$ is known to mediate the response of pericytes to inflammation by stimulating the formation of BMPs. Nevertheless, a role for RANKL has not yet been clearly established in the pathogenesis of arterial calcification, even though circumstantial evidence suggesting its involvement is very strong [7]. BMPs increase the levels of RANKL and suppress osteoprotegerin [17]. RANKL has also been shown to increase aortic calcification in vitro through enhanced MSX and wingless-type MMTV integration site (WNT) signalling, the pathway that mediates the effects of oxidative stress; this effect, moreover, was abolished by the TNF antagonist, infliximab [41]. Recent evidence has demonstrated that calcification of VSMCs, in vivo and in vitro, is enhanced by RANKL, apparently through a pathway that is dependent on RANK, NFKB and BMP-4 [42].

While osteoprotegerin may therefore antagonise any direct action of RANKL, it is possible that its dominant protective effects in MAC are twofold: (1) suppression of osteoclast activation by RANKL and hence reduced liberation of calcium and phosphate from bone into the circulation; and (2) inhibition of apoptosis of osteogenic cells by TRAIL $[10,39]$. Osteoprotegerin has also been shown to accumulate in the arterial wall in diabetes, which may reflect a compensatory mechanism or result from the actions of pro-inflammatory cytokines [43].

Nitric oxide Nitric oxide has been shown to inhibit calcification and osteoblastic transformation of VSMCs in vitro, an effect that has been shown to be mediated through inhibition of the actions of TGF- $\beta$ and its downstream effects on the phosphorylation of SMAD proteins and of plasminogen activator inhibitor-1 [44].

$H D L$ The administration of HDL to CVCs in vitro reduces alkaline phosphatase activity (a marker of osteogenic transformation of CVCs by BMPs), including that stimulated by pro-inflammatory cytokines IL-1 $\beta$ and IL-6. Prolonged administration of HDL to CVCs reduces calcification [45].

Intra-arterial forces Interestingly, the increasing intraarterial systolic pressure that characterises arteriosclerosis can itself augment the process of calcification. Thus levels of NFKB and BMPs are enhanced by increased pressure applied to endothelial cells in vitro [46]. External force has also been shown to increase RANKL production by osteoblasts, with particular changes induced by changes in cyclical or oscillatory forces [47].

\section{Chronic kidney disease}

Arterial calcification is common in established renal failure, with the main aetiological factors being vitamin D deficiency (and associated secondary hyperparathyroidism, which increases bone break-down) and hyperphosphataemia [11]. Vitamin D deficiency and elevated parathyroid hormone lead to increased levels of RANKL. Phosphate is the key trigger for the formation of calcium phosphate in matrix vesicles and non-apoptotic osteogenic cells. Loss of the calcification inhibitor, fetuin-A, with declining GFR has also been implicated [11].

It is also established that chronic kidney disease is associated with increased circulating concentrations of osteoprotegerin, which correlate with increased arterial calcification and with increased cardiovascular and allcause mortality [48]. Excretion of hydroxyproline is increased in patients with type 2 diabetes and microalbuminuria, suggesting increased bone turnover through activation of osteoclasts by RANKL [49]. Similarly, elevated circulating concentrations of osteoprotegerin (reflecting activation of the RANKL/osteoprotegerin pathway) have been shown in type 1 and type 2 diabetes complicated by albuminuria [50]. Moreover, urinary albumin excretion in patients with diabetes is associated with calcification of coronary and peripheral arteries [51].

\section{Factors that potentiate arterial wall calcification in diabetes}

Metabolic and hormonal factors Intracellular glucose induces tissue damage through four discrete mechanisms: (1) activation of the polyol pathway resulting in increased oxidative stress; (2) induction of an inflammatory response by AGE; (3) activation of the protein kinase-C pathway, leading to decreasing nitric oxide and increasing endothelin-1; and (4) stimulation of $N$-acetyl glucosamine via the hexosamine pathway, which causes increased plasminogen activator inhibitor-1 and TGF- $\beta$ [52]. Each and all of these could lead to activation of the processes leading to upregulation of the pathways that promote calcification of the arterial wall. Recently, it was suggested that insulin (or selective insulin resistance) may be directly involved in the process of arterial calcification [43]. The association is complex, since insulin can promote and inhibit the calcification process, depending on cellular responsiveness [43, 53].

Activation of the RANKL/osteoprotegerin signalling pathway Abundant epidemiological and clinical data show that diabetes is associated with increased circulating concen- 
trations of osteoprotegerin and that these correlate with arterial calcification, clinical cardiovascular disease and allcause mortality rates in both cross-sectional and prospective studies [54-58]. Serum concentrations of osteoprotegerin in diabetes correlate with systolic blood pressure and brachial-ankle pulse wave velocity (as a measure of arterial wall stiffness) [59]. While it has been generally accepted that increased concentrations of osteoprotegerin reflect generalised activation of the RANKL/osteoprotegerin system, Secchiero and colleagues [60] found that although osteoprotegerin was increased in patients with diabetes, total RANKL concentrations were not and free RANKL, in fact, was significantly reduced. This observation awaits confirmation now that assays for RANKL are more readily available.

Circulating concentrations of osteoprotegerin have been shown to be particularly elevated when diabetes is accompanied by microvascular complications, such as microalbuminuria and retinopathy [50]. This may reflect a generalised process mediated, at least in part, by increased activity of the RANKL/osteoprotegerin pathway and linked to widespread endothelial changes. However, the relationship between osteoprotegerin concentrations and both retinopathy and proteinuria may not be directly causal. The occurrence of proteinuria and retinopathy is closely linked to that of DSN, with strong circumstantial evidence suggesting that DSN may promote arterial calcification. A significant contribution by DSN would also explain the observation that MAC is most marked in the distal arteries, as originally noted by Mönckeberg.

\section{Distal symmetrical neuropathy}

Sensory neuropathy Arterial calcification was noted in the feet of 15 of 20 patients with severe diabetic neuropathy [61] and was greater in patients with neuropathy than in controls [62]. Neuropathy was also more prevalent in a Veterans Administration population with arterial calcification than in those without [63]. Psyrogiannis and colleagues reported that calcification was present in $40 \%$ of people whose diabetes was complicated by neuropathy [51]. Arterial calcification is also increased in other conditions associated with DSN, although not to as great an extent as in diabetes.

Other circumstantial evidence indicating the possible importance of neuropathy in the pathogenesis of arterial calcification is the arterial calcification observed in radiological images of $80 \%$ to $90 \%$ of patients who had or had previously had acute Charcot's disease; a higher percentage than in any other clinical group studied [64]; Acute Charcot's foot is a complication of DSN, and which is associated with prolonged inflammation. Such inflamma- tion could increase the prevalence of calcification through increased levels of pro-inflammatory cytokines and the RANKL/osteoprotegerin system [65]. Interestingly, arterial calcification has also been shown to be increased in Paget's disease of bone, a condition that is also characterised by increased RANKL levels and increased bone turnover [66].

Autonomic neuropathy It has long been suspected that arterial calcification may be the result of autonomic denervation. If so, this could explain the association with sensorimotor DSN, as autonomic neuropathy and DSN commonly co-exist in patients with diabetes. The most impressive evidence for involvement of the autonomic nervous system comes from the work of Goebel and Fuessel [67], who studied the prevalence and incidence of arterial calcification following unilateral and bilateral lumbar sympathectomy for critical ischaemia in 60 patients, of whom 19 had diabetes. The seemingly clear association between sympathectomy and the onset or worsening of arterial calcification on the treated side(s) strongly implicates autonomic denervation, provided lumbar sympathectomy can be assumed not to damage somatic, as well as sympathetic nerves.

Others have shown associations between clinical signs of autonomic dysfunction and arterial calcification in crosssectional studies, but great care is needed when interpreting conventional tests used to define autonomic neuropathy in patients who have arterial calcification. Impairment of vasoconstriction may be solely the result of structural changes in the arterial wall and need not necessarily indicate loss of sympathetic innervation. Similarly, the presence of arterial calcification could result in tachycardia, and both this and the systolic hypertension associated with arterial calcification could lead to reduced sinus arrhythmia, which is conventionally interpreted as a sign of vagal denervation of the heart. This may explain the relatively poor performance of tests of cardiovascular autonomic neuropathy in younger people with type 1 diabetes, when compared with pupillometry [68]. And although Forst and colleagues [69] observed a highly significant association between MAC and autonomic neuropathy identified by loss of sweat responses as well as by abnormal cardiovascular reflexes in diabetes, Mayfield et al. [63] found that the results of cardiovascular autonomic function tests did not fully explain the increased mortality rates associated with MAC.

Role of neuropeptides Any potentiation of arterial calcification by DSN is likely to be mediated through loss of neuropeptides, and especially neuropeptides of the calcitonin family, i.e. calcitonin gene-related peptide (CGRP), islet amyloid polypeptide (amylin), adrenomedullin and intermedin, all of which are known to be important in the 
regulation of bone metabolism [70]. Of these, the prime candidate at the level of the peripheral nerve is CGRP. Experimental diabetes complicated by neuropathy has been shown to result in downregulation of CGRP in nerves from rats and mice [71, 72]. In human diabetes, neuropathy has been shown in one small study to be associated with reduced nitric oxide synthase in bone, as well as with a trend towards reduction of CGRP [73].

CGRP has trophic and vasodilatory properties [74] and is known to be an important regulator of bone at the level of the osteoblast, with CGRP depletion leading to decreased bone formation [75]. Like calcitonin, CGRP also inhibits osteoclast maturation [76]. Both calcitonin and CGRP have been shown to inhibit the maturation of osteoclasts induced by RANKL [77]. Nevertheless, CGRP can also inhibit the synthesis of osteoprotegerin by osteoblasts, suggesting a bimodal, autoregulatory, action [78]. This is echoed by the finding that CGRP (as well as substance P) can induce in vitro formation of the pro-inflammatory cytokines, IL-1, IL-6 and TNF- $\alpha$, in human dental pulp cells [79].

CGRP may also play a key part in the healing of ligamentous damage in laboratory animals [67], a finding particularly relevant to acute Charcot's disease of diabetes. Hitherto, there has been no explanation for the increased dislocation of joints, which together with bone inflammation and fracture, characterises this condition. However, impaired ligamentous strength and healing as a result of underlying neuropathy and resultant loss of CGRP would provide such an explanation.

Neuropeptides and the sympathetic nervous system Bone and periosteum are richly innervated by CGRP-containing nerve fibres and run in close proximity to a dense mesh of sympathetic (tyrosine hydroxylase-positive) and sensory (NF200+) nerve terminals [80]. It is also thought that nerves in bone, which contain CGRP, substance $\mathrm{P}$ and vasoactive intestinal polypeptide, may relay central signals resulting from the action of leptin on the hypothalamus [75]. Leptin stimulates sympathetic $\beta 2$-adrenergic signalling, which inhibits osteoblastic function and favours bone resorption [81]. $\beta 2$-Adrenergic stimulation of a mouse bone marrow cell model with isoprenaline resulted in increased osteoclast activation via the action of RANKL, a process inhibited by administration of osteoprotegerin [82]. Neuropeptide $\mathrm{Y}$ is a co-transmitter with noradrenaline in sympathetic nerve terminals and inhibits the effect of the $\beta 2$-adrenergic agonist, isoprenaline, in stimulating bone resorption. It does not, however, inhibit the stimulatory effect of RANKL or 1,25-dihydroxycholecalciferol on osteoclasts [83]. Although knowledge of the processes involved is patchy, the evidence suggests close integration of neuropeptides and the sympathetic nervous system in the regulation of bone formation and turnover. Thus although virtually all the available evidence relates to bone, similar relationships could be involved in the development of arterial calcification, especially given that the signalling pathways are so similar.

Endocannabinoids and the sympathetic nervous system The final pathway possibly involved in the development of MAC is that of endocannabinoids. Here, once again, the available evidence comes from work on bone. Two endogenous endocannabinoids, anandamide and 2-arachidonoylglycerol are present in osteoblasts and osteoclasts, and it is likely that they modulate the effect of the sympathetic nervous system on bone resorption. Endocannabinoids induce production of NF$\mathrm{KB}$ in bone marrow dendritic cells [84].

\section{Implications of role of neuropathy in causing MAC}

The involvement of the nervous system, whether somatic or autonomic, in promoting MAC would explain the distal distribution of calcification in diabetes and other disorders of denervation. It also implies that the factors triggering MAC may be both local and systemic, even though systemic factors (such as hyperglycaemia, hyperlipidaemia, reactive oxygen species, circulating pro-inflammatory cytokines, phosphate retention) are the principal ones considered hitherto as a cause of MAC. Thus, the changes triggered by neuropathy will be largely confined to the tissues affected, regardless of whether the effect of denervation is exerted on the arterial wall (with increased RANKL, for example, or reduced osteoprotegerin being triggered by loss of CGRP) or whether the primary effect is on the bone. If the primary effect is on the bone, increased bone resorption could trigger calcification by releasing calcium and phosphate ions, which also has a predominantly local, rather than systemic effect.

\section{DSN as an independent risk factor for cardiovascular disease in diabetes}

If DSN has a role in the pathogenesis of arterial calcification and explains the distal distribution of calcification observed in diabetes, it is possible that it also has an independent effect on cardiovascular risk. Cardiovascular risk would be increased by rising arterial systolic pressure and widened pulse pressure, which results from loss of compliance in the stiffened wall. Ono and colleagues [85] reported that elevation of the ankle-brachial pressure index (as a marker of arteriosclerosis) was associated with allcause and cardiovascular mortality rates in a population of patients (with and without diabetes) on haemodialysis. Others have also noted the close relationship between 
arterial calcification, pulse wave velocity and cardiovascular mortality rates in chronic kidney disease patients [86].

DSN is not generally regarded as a risk factor for cardiovascular disease, yet a strong independent relationship was recently observed between peripheral sensory neuropathy and pulse pressure for cardiovascular and allcause mortality rates in the Eurodiab study of type 1 diabetes [87]. This observation confirms earlier observations made by Forsblom et al. [88] in patients with type 2 diabetes and by Coppini et al. [89] in a mixed population. However, no association was observed between cardiovascular mortality rates and sensory neuropathy in the UK Prospective Diabetes Study, and between all-cause and cardiovascular mortality rates and the presence of DSN in newly diagnosed type 2 diabetes at presentation (I. Stratton, National Screening Programmes for Diabetic Retinopathy, Cheltenham General Hospital, Cheltenham, UK, personal communication). An association between mortality rates and neuropathy does not appear to have been sought in the Danish [90], WHO Multinational [91] and Pittsburgh [92] studies. Nevertheless, the possibility that DSN confers an independent cardiovascular risk merits further study. If it is confirmed, we suggest that it is likely to result largely from a neuropathy-mediated effect on cardiovascular calcification.

\section{Therapeutic implications}

Improved understanding of the causes and effects of MAC would have immediate clinical and therapeutic implications. Specific interventions to prevent or reverse arterial calcification might include the use of antagonists to TNF- $\alpha$ and RANKL, such as infliximab, etanercept and denosumab. However, agents currently in more widespread clinical use might also have a role. Thus HMG-Co-A reductase inhibitors (statins) have been reported to inhibit phosphate-induced apoptosis of smooth muscle cells [93], but the evidence is ambiguous $[94,95]$ and simvastatin did not reverse established arterial calcification in one human study [96]. The potential benefit of peroxisome proliferatoractivated receptor (PPAR) $\gamma$ agonists has yet to be fully explored, although their use is known to be associated with decreased expression of pro-inflammatory cytokines and they have also been reported to inhibit neovascularisation. However, the known tendency of PPAR $\gamma$ to augment bone break-down could potentially increase arterial calcification. Finally, the use of ACE inhibitors and angiotensin receptor blocking agents has been shown to be associated with reduced progression of coronary artery calcification in type 1 diabetes [97], an apparent effect that requires further study.

Recent work has also highlighted the potentially catastrophic adverse effect of MAC on cardiovascular compensatory mechanisms, especially in patients undergoing haemodialysis. Thus, dialysis has been shown to be associated with a major reduction in myocardial function [98] and distal limb oxygenation [99], both of which could contribute to the very high mortality rates associated with dialysis, as well as to its close association with the onset of foot disease in diabetes and with amputation [100]. Strategies to reduce the impact of these consequences of dialysis are urgently needed and should include careful review of the benefits and costs of aggressive management of systolic hypertension patients with MAC.

Acknowledgements We thank Y. Alexander for kindly donating Fig. 1, and I. Stratton (National Screening Programmes for Diabetic Retinopathy, Cheltenham General Hospital, Cheltenham, UK) for providing unpublished analyses of the UKPDS database.

Duality of interest The authors declare that there is no duality of interest associated with this manuscript.

\section{References}

1. Mönckeberg JG (1903) Uber die reine Mediaverkalkung der Exrtremitätenarterien und ihr Verhalten zur Arteriosklerose. Virchows Arch (Pathol Anat) 171:141-167 (article in German)

2. Everhart JE, Pettit DJ, Knowler WC, Rose FA, Bennett PH (1988) Medial artery calcification and its association with mortality and complications of diabetes. Diabetologia 31:1623

3. Lehto S, Niskanen L, Suhonen M, Rönnemaa T, Laakso M (1996) Medial artery calcification: a neglected harbinger of cardiovascular complications in non-insulin dependent diabetes mellitus. Arterioscler Thromb Vasc Biol 16:978-983

4. Virchow R (1863) Cellular pathology as based upon physiological and pathological histology. Dover, New York

5. Vattikuti R, Towler DA (2003) Osteogenic regulation of vascular calcification: an early perspective. Am J Physiol: Endocrinol Metab 286:E686-E696

6. Neven E, Dauwe S, De Broe ME, D'Hause PC, Persy V (2007) Endochondral bone formation is involved in media calcification in rats and in men. Kidney Int 72:574-581

7. Collin-Osdoby P (2004) Regulation of vascular calcification by osteoclast regulatory factors RANKL and osteoprotegerin. Circ Res 95:1046-1057

8. Abedin M, Tintut Y, Demer LL (2004) Vascular calcification: mechanisms and clinical ramifications. Arterioscler Thromb Vasc Biol 24:1161-1170

9. Giachelli CM, Speer MY, Li X, Rajachar RM, Yang H (2005) Regulation of vascular calcification: roles of phosphate and osteopontin. Circ Res 96:717-722

10. Hofbauer LC, Brueck CC, Sanahan CM, Schoppet M, Dobnig H (2007) Vascular calcification and osteoporosis-from clinical observation towards molecular understanding. Osteoporos Int 18:251-259

11. Moe SM, Chen NX (2004) Pathophysiology of vascular calcification in chronic kidney disease. Circ Res 95:560-567

12. Abedin M, Tintut Y, Demer LL (2004) Mesenchymal stem cells and the artery wall. Circ Res 95:671-676

13. Boström K, Watson KE, Horn S, Wortham C, Hennan IM, Demer LL (1993) Bone morphogenetic protein expression in human atherosclerotic lesions. J Clin Invest 91:1800-1809 
14. Mantell DJ, Owens PE, Bundred NJ, Mawer EB, Canfield AE (2000) 1 alpha, 25-dihydroxyvitamin $\mathrm{D}(3)$ inhibits angiogenesis in vitro and in vivo. Circ Res 87:214-220

15. Kirton JP, Crofts NJ, George SJ, Brennan K, Canfield AE (2007) Wnt/beta-catenin signalling stimulates chondrogenic and inhibits adipogenic differentiation of pericytes: potential relevance to vascular disease. Circ Res 101:581-589

16. Shao JS, Cai J, Towler DJ (2006) Molecular mechanisms of vascular calcification: lessons learned from the aorta. Arterioscler Thromb Vasc Biol 26:1423-1430

17. Nguyen KQ, Olesen P, Ledet T, Rasmussen LM (2007) Bone morphogenetic proteins regulate osteoprotegerin and its ligands in human vascular smooth muscle cells. Endocr 32:52-58

18. Tyson KL, Reynolds JL, McNair R, Zhang Q, Weissberg PL, Shanahan CM (2003) Osteo/chondrocytic transcription factors and their target genes exhibit distinct patterns of expression in human arterial calcification. Arterioscler Thromb Vasc Biol 23:489-494

19. Eijken M, Swagemakers S, Koedam M, Steenbergen C, Derkx P, Uitterlinden AG (2007) The activin A-follistatin system: potent regulator of human extravascular matrix mineralization. FASEB J 21:2949-2960

20. Bartholin L, Guindon S, Martel S, Corbo L, Rimokh R (2007) Identification of NF-kappaB responsive elements in follistatin related gene (FLRG) promoter. Gene 393:153-162

21. Hayashi Y, Maeshima K, Got F, Kojima I (2007) Activin A as a critical mediator of capillary formation: interaction with the fibroblast growth factor action. Endocr J 54:311-318

22. Pavelock KA, Girard BM, Schutz KC, Braas KM, May V (2007) Bone morphogenetic protein down-regulation of neuronal pituitary adenylate cyclase-activating polypeptide and reciprocal effects on vasoactive intestinal peptide expression. J Neurochem 100:603-616

23. Anderson HC (1995) Molecular biology of matrix vesicles. Clin Orthop Relat Res 314:266-280

24. Clarke MC, Littlewood TD, Figg N, Maguire JJ, Davenport AP, Goddard M (2008) Chronic apoptosis of vascular smooth muscle cells accelerates atherosclerosis and promotes calcification and medial degeneration. Circ Res 102:1529-1538

25. Sims TJ, Rasmussen LM, Oxlund H, Bailey AJ (1996) The role of glycation cross-links in diabetic vascular stiffening. Diabetologia 39:946-951

26. Greenwald SE (2007) Ageing of the conduit arteries. J Pathol 211:157-172

27. Simionescu A, Simionescu DT, Vyavahare NR (2007) Osteogenic responses in fibroblasts activated by elastin degradation products and transforming growth factor- $\beta 1$. Am J Pathol 171:116-123

28. Collett GDM, Canfield AE (2005) Angiogenesis and pericytes in the initiation of ectopic calcification. Circ Res 96:930-938

29. Wang Y, Wan C, Deng L et al (2007) The hypoxia-inducible factor $\alpha$ pathway couples angiogenesis to osteogenesis during skeletal development. J Clin Invest 117:1616-1626

30. Li X, Hsueh-Ying Y, Giachelli CM (2006) Role of the sodiumdependent cotransporter, Pit-1, in vascular smooth muscle cell calcification. Circ Res 98:905-912

31. Burke AP, Kolodgie FD, Virmani R (2007) Fetuin-A, valve calcification, and diabetes: what do we understand? Circulation $115: 2464-2467$

32. Westenfeld R, Jahnen-Dechent W, Ketteler M (2007) Vascular calcification and fetuin-A deficiency in chronic kidney disease. Trends Cardiovasc Med 17:124-128

33. Boström K, Tsao D, Shen S, Wang Y, Demer LL (2001) Matrix GLA protein modulates differentiation induced by bone morphogenetic protein-2 in $\mathrm{C} 3 \mathrm{H} 10 \mathrm{~T} 1 / 2$ cells. J Biol Chem 276:14044-14052
34. Price PA, Caputo JM, Williamson MK (2002) Bone origin of the serum complex of calcium, phosphate, fetuin, and matrix Gla Protein: biochemical evidence for the cancellous boneremodelling compartment. J Bone Miner Res 7:1171-1179

35. Wada T, McKee MD, Steitz GCM (1999) Calcification of vascular smooth muscle cell cultures: inhibition by osteopontin. Circ Res 84:166-178

36. Takemoto M, Yokote K, Nishimura M et al (2000) Enhanced expression of osteopontin in human diabetic artery and analysis of its functional role in accelerated atherogenesis. Arterioscler Thromb Vasc Biol 20:624-628

37. Hofbauer LC, Schoppet M (2001) Osteoprotegerin: a link between osteoporosis and arterial calcification? Lancet 358:257-259

38. Rogers A, Eastell R (2005) Circulating osteoprotegerin and receptor activator for nuclear factor kappaB ligand: clinical utility in metabolic bone disease assessment. J Clin Endocrinol Metab 90:6323-6331

39. Bucay N, Safosi I, Dunstan CR et al (1998) Osteoprotegerindeficient mice develop early onset osteoporosis and arterial calcification. Genes Dev 12:1260-1268

40. Schoppett M, Al-Fakhari N, Franke FE et al (2004) Localization of osteoprotegerin, tumor necrosis factor-related apoptosisinducing ligand, and receptor activator of nuclear factor- $\mathrm{kB}$ ligand in Mönckeberg's sclerosis and atherosclerosis. J Clin Endocrinol Metab 89:4104-4112

41. Al-Aly Z (2008) Arterial calcification: a tumor necrosis factoralpha mediated vascular Wnt-opathy. Transl Res 151:233-239

42. Panizo S, Cardus A, Encinas M et al (2009) RANKL increases vascular smooth muscle cell calcification through a RANKBMP4-dependent pathway. Circ Res 104:1041-1048

43. Olesen P, Ledet T, Rasmussen LM (2005) Arterial osteoprotegerin: increased amounts in diabetes and modifiable synthesis from vascular smooth muscle cells by insulin and TNF-alpha. Diabetologia 48:561-568

44. Kanno Y, Into T, Lowenstein CJ, Matsushita K (2008) Nitric oxide regulates vascular calcification by interfering with TGFsignalling. Cardiovasc Res 77:221-230

45. Parhami F, Basseri B, Hwang J, Tintut Y, Demer LL (2002) High-density lipoprotein regulates calcification of vascular cells. Circ Res 91:570-576

46. Csiszar A, Smith KE, Koller A, Kaley G, Edwards JG, Ungvari Z (2005) Regulation of bone morphogenetic protein-2 expression in endothelial cells. Circulation 111:2364-2372

47. Kim CH, You L, Yellowley CE, Jacobs CR (2006) Oscillatory fluid flow-induced shear stress decreases osteoclastogenesis through RANKL and OPG signalling. Bone 39:1043-1047

48. Jorsal A, Tarnow L, Flyvbjerg A, Parving HH, Rossing P, Rasmussen LM (2008) Plasma osteoprotegerin levels predict cardiovascular and all-cause mortality and deterioration of kidney function in type 1 diabetic patients with nephropathy. Diabetologia 51:2100-2107

49. Selby PL, Shearing PA, Marshall SM (1995) Hydroxyproline excretion is increased in diabetes mellitus and related to the presence of microalbuminuria. Diabet Med 12:240-243

50. Knudsen ST, Foss CH, Poulsen PL, Andersen NH, Mogensen CE, Rasmussen LM (2006) Increased plasma concentrations of osteoprotegerin in type 2 diabetic patients with microvascular complications. Eur J Endocrinol 149:39-42

51. Psyrogiannis A, Kyriazopoulou V, Vagenakis AG (1999) Medial arterial calcification is frequently found in patients with microalbuminuria. Angiology 50:971-975

52. Brownlee M (2005) The pathobiology of diabetic complications: a unifying mechanism. Diabetes 54:1615-1625

53. Wang CC, Sorribas V, Sharma G, Levi M, Draznin B (2007) Insulin attenuates vascular smooth muscle calcification but 
increases vascular smooth muscle cell phosphate transport. Atherosclerosis 195:e65-e75

54. Browner WS, Lui L-Y, Cummings SR (2001) Associations of serum osteoprotegerin levels with diabetes, stroke, bone density, fractures and mortality in elderly women. J Clin Endocrinol Metab 86:631-637

55. Schoppett M, Sattler AM, Schaefer JR, Herzum M, Maisch B, Hofbauer LC (2003) Increased osteoprotegerin serum levels in men with coronary artery disease. J Clin Endocrinol Metab 88:1024-1028

56. Avignon A, Sultan A, Piot A et al (2005) Osteoprotegerin is associated with silent coronary artery disease in high-risk but asymptomatic type 2 diabetic patients. Diabetes Care 28:21762180

57. Rasmussen LM, Tarnow L, Hansen TK, Parving H-H, Flyvbjerg A (2006) Plasma osteoprotegerin levels are associated with glycaemic status, systolic blood pressure, kidney function and cardiovascular morbidity in type 1 diabetic patients. Eur $\mathrm{J}$ Endocrinol 154:75-81

58. Anand DV, Lahiri A, Lim E, Hopkins D, Corder R (2006) The relationship between plasma osteoprotegerin levels and coronary artery calcification in uncomplicated type 2 diabetic subjects. $\mathrm{J}$ Am Coll Cardiol 47:1850-1857

59. Kim SM, Lee J, Ryu OH et al (2005) Serum osteoprotegerin levels are associated with inflammation and pulse wave velocity. Clin Endocrinol (Oxf) 63:594-598

60. Secchiero P, Corallini F, Pandolfi A et al (2006) An increased osteoprotegerin serum release characterizes the early onset of diabetes mellitus and may contribute to endothelial cell dysfunction. Am J Pathol 169:2236-2244

61. Edmonds ME, Morrison N, Laws JW, Watkins PJ (1982) Medial arterial calcification and diabetic neuropathy. BMJ 284:928-930

62. Young MJ, Adams JE, Anderson GF, Boulton AJ, Cavanagh PR (1993) Medial artery calcification in the feet of diabetic patients and matched non-diabetic controls. Diabetologia 36:615-621

63. Mayfield JA, Caps MT, Boyko EJ, Ahroni JH, Smith DG (2002) Relationship of medial arterial calcinosis to autonomic neuropathy and adverse outcomes in a diabetic veteran population. $\mathrm{J}$ Diabet Compl 16:165-171

64. Sinha S, Munichoodappa CS, Kozak GP (1972) Neuroarthropathy (Charcot joints) in diabetes mellitus (clinical study of 101 cases). Medicine (Baltimore) 51:191-210

65. Jeffcoate WJ, Game F, Cavanagh PR (2005) The role of proinflammatory cytokines in the cause of neuropathic osteoarthropathy (acute Charcot foot) in diabetes. Lancet 366:20582061

66. Laroche M, Delmotte A (2005) Increased arterial calcification in Paget's disease of bone. Calcif Tissue Int 77:129-133

67. Goebel FD, Füessel HS (1983) Mönckeberg's sclerosis after sympathetic denervation in diabetic and non-diabetic subjects. Diabetologia 24:347-350

68. Maguire AM, Craig ME, Craighead A et al (2007) Autonomic nerve testing predicts the development of complications. Diabetes Care 30:77-82

69. Forst T, Pfützner A, Kann P, Lobmann R, Schäfer H, Beyer J (1995) Association between diabetic-autonomic-C-fibre-neuropathy and medial wall calcification in the outcome of trophic foot lesions. Exp Clin Endocrinol Diabetes 103:94-98

70. Naot D, Cornish J (2008) The role of peptides and receptors of the calcitonin family in the regulation of bone metabolism. Bone 43:813-818

71. Zochodne DW, Verge VM, Cheng C, Sun H, Johnston J (2001) Does diabetes target ganglion neurones ? Progressive sensory neurone involvement in long-term experimental diabetes. Brain 124:2319-2334
72. Jiang Y, Nyengaard JG, Zhang JS, Jakobsen J (2004) Selective loss of calcitonin gene-related peptide-expressing primary sensory neurons of the a-cell phenotype in early and experimental diabetes. Diabetes 53:2669-2675

73. La Fontaine J, Harkless LB, Sylvia VL, Carnes D, Heim-Hall J, Jude E (2008) Levels of endothelial nitric oxide synthase and calcitonin gene-related peptide in the Charcot foot: a pilot study. J Foot Ankle Surg 47:424-429

74. McDougall JJ, Yeung G, Leonard CA, Bray RC (2000) A role for calcitonin gene-related peptide in rabbit knee joint ligament healing. Can J Physiol Pharmacol 78:535-540

75. Lerner UH (2006) Deletions of genes encoding calcitonin/alphaCGRP, amylin and calcitonin receptor have given new and unexpected insights into the function of calcitonin receptors and calcitonin receptor-like receptors in bone. J Musculoskelet Neuronal Interact 6:87-95

76. Cornish J, Callon KE, Bava U, Kamona SA, Cooper GJ, Reid IR (2001) Effects of calcitonin, amylin, and calcitonin gene-related peptide on osteoclast development. Bone 29:162-168

77. Mancini L, Moradi-Bidhendi N, Brandi ML, Perretti M, MacIntyre I (2001) Modulation of the effects of osteoprotegerin (OPG) ligand in a human leukemic cell line by OPG and calcitonin. Biochem Biophys Res Comm 279:391-397

78. Villa I, Mrak E, Rubinacci A, Ravasi F, Guidobono F (2006) CGRP inhibits osteoprotegerin production in human osteoblastlike cells via cAMP/PKA-dependent pathway. Am J Physiol Cell Physiol 291:C529-C537

79. Yamaguchi M, Kojima T, Kanekawa M, Alhara N, Nogimura A, Kasai K (2004) Neuropeptides stimulate production of interleukin-6, and tumor necrosis factor-alpha in human dental pulp cells. Inflamm Res 53:199-204

80. Martin CD, Jimenez-Andrade JM, Ghilardi JR, Mantyh PW (2007) Organization of a unique net-like meshwork of CGRP+ sensory fibers in the mouse periosteum: implications for the generation and maintenance of bone fracture pain. Neurosci Lett 427:148-152

81. Elefteriou E, Ahn JD, Takeda S et al (2005) Leptin regulation of bone resorption by the sympathetic nervous system. Nature 434:514-520

82. Ishizuka K, Hirukawa K, Nakamura H, Togari A (2005) Inhibitory effect of CGRP on osteoclast formation by mouse bone marrow cells treated with isoproterenol. Neurosci Lett 379:47-51

83. Armano S, Atai M, Goto S, Togari A (2007) Inhibitory effect of NPY on isoprenaline-induced osteoclastogenesis in mouse bone marrow cells. Biochim Biophys Acta 1770:966-973

84. Do Y, McKallip RJ, Nagarkatti M, Nagarkatti PS (2004) Activation through cannabinoid receptors 1 and 2 on dendritic cells triggers NF-kappa-B-dependent apoptosis: novel role for endogenous and exogenous cannabinoids in immunoregulation. $\mathrm{J}$ Immunol 173:2373-2382

85. Ono K, Tsuchida A, Kawai H et al (2003) Ankle-brachial blood pressure index predicts all-cause mortality in haemodialysis patients. J Am Soc Nephrol 14:1591-1598

86. Tussaint ND, Kerr PG (2007) Vascular calcification and arterial stiffness in chronic kidney disease: implications and management. Nephrology (Carlton) 12:500-509

87. Soedamah-Muthu SS, Chaturvedi N, Witte DR, Stevens LK, Porta M, Fuller JP (2008) Relationship between risk factors and mortality in type 1 diabetic patients in Europe. Diabetes Care 31:1360-1366

88. Forsblom CM, Sane T, Groop PH et al (1998) Risk factors for mortality in Type II (non-insulin dependent) diabetes: evidence of a role for neuropathy and a protective effect of HLA-DR4. Diabetologia 41:1253-1262 
89. Coppini DV, Bowtell PA, Weng C, Young PJ, Sönksen PH (2000) Showing neuropathy is related to increased mortality in diabetic patients - a survival analysis using an accelerated failure time model. J Clin Epidemiol 53:519-523

90. Rossing P, Hougaard P, Borch-Johnsen K, Parving H-H (1996) Predictors of mortality in insulin-dependent diabetes: 10 year observational follow-up study. BMJ 313:779-784

91. Stephenson JM, Kenny S, Stevens LK, Fuller JH, Lee E (1995) Proteinuria and mortality in diabetes: the WHO multinational study of vascular disease in diabetes. Diabet Med 12:149-155

92. Olson JC, Erbey JR, Williams KV et al (2002) Subclinical atherosclerosis and estimated glucose disposal rate as predictors of mortality in type 1 diabetes. Ann Epidemiol 12:331-337

93. Son BK, Kozaki K, Iijima K et al (2006) Statins protect human aortic smooth muscle cells from inorganic phosphate-induced calcification by restoring Gas6-Axi survival pathway. Circ Res 98:1024-1031

94. Trion A, Schutte-Bart C, Bax WH, Jukema JW, van der Laarso A (2008) Modulation of calcification of vascular smooth muscle cells in culture by calcium antagonists, statins, and their combination. Mol Cell Biochem 308:25-33
95. Xu YG, Zhou SH, Li YG et al (2007) The mechanism underlying vascular smooth muscle cell apoptosis induced by atorvastatin may be mainly associated with down-regulation of survivin expression. Cardiovasc Drugs Ther 21:145-153

96. Terry JG, Carr JJ, Kouba EO et al (2007) Effect of simvastatin (80 $\mathrm{mg}$ ) on coronary and abdominal aortic calcium (from the coronary artery calcification treatment with zocor [CATZ] study). Am J Cardiol 99:1714-1717

97. Maahs DM, Snell-Bergeon JK, Kinney GL et al (2007) ACE-I/ $\mathrm{ARB}$ treatment in type 1 diabetes patients with albuminuria is associated with lower odds of progression of coronary artery calcification. J Diab Complicat 21:273-279

98. McIntyre CW (2007) The functional cardiovascular consequences of vascular calcification. Semin Dialysis 20:123-129

99. Hinchliffe RJ, Kirk B, Bhattacharjee D, Roe S, Jeffcoate W, Game F (2006) The effect of haemodialysis on transcutaneous oxygen tension in patients with diabetes - a pilot study. Nephrol Dial Transplant 21:1981-1983

100. Game FL, Chipchase SY, Hubbard R, Burden RP, Jeffcoate WJ (2006) Temporal association between the incidence of foot ulceration and the start of dialysis in diabetes mellitus. Nephrol Dial Transplant 21:3207-3210 